Article

\title{
Physiochemical Quality and Sensory Characteristics of koji Made with Soybean, Rice, and Wheat for Commercial doenjang Production
}

\author{
Hyun Hee Hong and Mina K. Kim * (D) \\ Department of Food Science and Human Nutrition, and Fermented Food Research Center, \\ Jeonbuk National University, 567 Baekjedaero, Deokjin-gu, Jeonju-si, Jeonbuk 54896, Korea; \\ hhh2439876@naver.com \\ * Correspondence: minakim@jbnu.ac.kr; Tel.: +82-63-270-3879
}

Received: 9 June 2020; Accepted: 22 July 2020; Published: 23 July 2020

check for updates

\begin{abstract}
The purpose of this study was to compare the physiochemical quality characteristics and sensory profiles of three types of koji: soybean, rice, and wheat koji. Koji is made by inoculating Aspergillus oryzae following the standard method of manufacturing. The physiochemical characteristic and sensory profiles were performed after fermenting samples of $k$ oji for a $72 \mathrm{~h}$ period. The physiochemical quality characteristics that were tested include $\mathrm{pH}$, moisture content, color, acidity, TA, amino-type nitrogen content, reducing- and total-sugar content, and alcohol content; the enzymatic activities that were tested include amylase ( $\alpha$ - and $\beta-$ ) and protease (neutral and acidic) activities. A descriptive sensory analysis was conducted on three types of koji with a highly trained sensory panel $(n=7)$ using the Spectrum $^{\mathrm{TM}}$ Method. Differences in physiochemical and sensory profiles were observed on three koji samples $(p<0.05)$. Soybean koji had higher values in acid and TA, while rice koji had the highest values in reducing and total sugar, at $90.3 \mathrm{mg} / \mathrm{g}$ and $107.5 \mathrm{mg} / \mathrm{g}$ respectively. Wheat $\mathrm{koji}$ had the lowest values in protease activities. The flavor profile of soybean koji was characterized by bean sprout, cracker, and cheonggukjang aromatics; that of rice koji was characterized by overripe banana, solvent, syrup, and parboiled rice aromatics; and that of wheat koji was characterized by woody and roasted aromatics.
\end{abstract}

Keywords: koji; physiochemical quality characteristics; descriptive analysis; flavor

\section{Introduction}

Doenjang, fermented soybean paste, is a traditional Korean food ingredient. While the traditional doenjang-making process depends heavily on fermentation, companies have developed rapid fermentation methods for commercially available, mass-produced doenjang [1,2]. One method of manufacturing commercial doenjang is by using koji, which is made by inoculating Aspergillus oryzae in grainy materials such as soybean, rice, and wheat, and fermenting it for 48 to $72 \mathrm{~h}$. Once the koji is well fermented, it is mixed with boiled soybean and fermented another month [3]. Using koji in doenjang-making can speed up the fermentation process. While traditional method takes about six months to several years to make doenjang, the commercial method using koji only takes one month to complete [1]; thus, food companies preferred to use koji for their doenjang manufacturing process.

Koji primarily serves as a starter for fermented foods and is widely used in the manufacturing of various Asian fermented foods in addition to doenjang, such as soy sauce, miso, sake, mirin, and gochujang (red pepper paste) [4,5]. Koji naturally contains large quantities of enzymes such as amylase and protease produced by molds, which convert starch and protein into fermented sugar and amino acids [6,7]. During protein-degradation process and the conversion of starch into sugar, the versatile flavors of doenjang are also developed. Therefore, the final food products using koji 
are greatly influenced by the qualities of koji [8]. While nuruk, another category of starter culture in fermented foods in Korea, is composed of various microorganisms naturally present in the environment, $k o j i$ is made by a single microorganism under controlled fermentation conditions [9].

In order to develop the commercialized doenjang using koji, various studies were previously conducted in order to optimize the fermentation condition of koji and doenjang made with koji. For example, the optimum conditions of enzymatic activities including $\alpha$-amylase, in koji made with rice, barley was reported [7]. Their study reported that increases of $\alpha$-amylase activity was observed during exponential growth stage of $A$. oryzae, and decrease of enzymatic activities when $A$. oryzae reaches the stationary growth phase. Their work utilized $A$. oryzae in steamed rice and barley and fermented for $118 \mathrm{hrs}$ at $28-32{ }^{\circ} \mathrm{C}$ with controlled relative humidities. Similarly, changes of enzymatic activities bythe growth of Aspergillus oryzae S. during soybean-based koji fermentation was investigated previously, and their study reported that increase of $\mathrm{pH}$ caused by enzymatic activities such as protease and amylase activities of 84.4 and $200 \mathrm{U} / \mathrm{g}$, during fermentation [5]. The changes in quality characteristics of doenjang prepared with soybean koji during fermentation were investigated and reported that Doenjang made with soybean koji in which prepared with Bacillus subtillus 3-B-1 and Aspergillus oryzae 6-M-1 can provide sensory characteristics similar to that of traditionally prepared doenjang [10]. Earlier than their study, changes of biochemical properties and enzymatic activities of soy sauce prepared with mixture of soybean and wheat flour koji were reported [11]. Besides enzymatic activities and physiochemical quality activities of koji and doenjang with koji, analysis of functionality of koji was also reported such as isoflavone transformation during soybean koji preparation process and subsequent doenjang fermentation process [12].

The above-mentioned studies focused on the final products that contain koji, instead of investigating the quality of koji itself. Considering the influence of koji on the flavor of the final products in which it is used, it is necessary to comprehensively determine the characteristics of koji. To date, studies focusing on koji made with different sources of starchy materials have not been well documented. Therefore, the purpose of this study was to determine the physiochemical qualities and sensory characteristics of koji prepared with three different ingredients: soybean, rice, and wheat.

\section{Materials and Methods}

\subsection{Koji Sample Preparation}

Koji samples were prepared according to the standard manufacturing method used by previous studies $[13,14]$. Three different ingredients for koji preparation were selected: soybean, rice, and wheat flour (Beksul ${ }^{\circledR}$ soft flour, CJ CheilJedang, Yangsan, Korea). These ingredients were purchased from a local grocery store in Jeonju, Jeollabuk-do, Korea. Aspergillus oryzae in powder form (Suwon Fermentation Food Research Institute, Seongnam, Korea) was purchased at a food market in Yeswine, Boen, Korea. For the preparation of soybean and rice koji, soybean and rice were rehydrated at room temperature for $12 \mathrm{~h}$ while wheat flour was thoroughly blended with $20 \%(\mathrm{w} / \mathrm{v})$ distilled water. Once fully hydrated, all were autoclaved (LAC-5060S, Lab Tech, Namyangju, Korea) for $40 \mathrm{~min}$ at $121{ }^{\circ} \mathrm{C}$ at $0.1 \mathrm{mpa}$. Then, the soybean and rice were finely blended using a food processor (NINJA BL682KR, Hai Xin Technology Company, Shenzhen, China) at $19,354 \times g$ for one minute, and all equipment used for blending was prepared aseptically in order to minimize the introduction of undesirable microorganisms. Then, $0.2 \%(w / w)$ of Aspergillus oryzae powder was inoculated to the soybean, rice, and wheat powder and incubated at $35^{\circ} \mathrm{C}$ for $72 \mathrm{~h}$. All the koji samples were mixed using a sterilized spoon every $24 \mathrm{~h}$ to aerate the koji mixture. The koji was stored at a temperature of $-80^{\circ} \mathrm{C}$ for further analysis. Koji samples were produced three times independently.

\subsection{Physiochemical Quality Characteristic Analyses}

Physicochemical quality characteristics were analyzed following the standard methods of analysis in the Korean Food Standard Codex and a previous study [10,14], with minor modifications. All chemical compounds were purchased from the chemicals company Sigma-Aldrich (St. Louis, MO, USA). 
The physiochemical quality characteristics of moisture, color, $\mathrm{pH}$, titratable acidity (TA), acidity, salinity, amino-type nitrogen content, alcohol content, and reducing- and total-sugar content of koji were analyzed. Moisture content was measured using a moisture analyzer (WBA-110M, Daihan Scientific Co., Wonju, Korea). Color was determined using a color analyzer (CR-10 Plus, Konica Minolta, Tokyo, Japan). Titratable acidity and $\mathrm{pH}$ were analyzed on $10 \%(w / v)$ diluted $k o j i$ with distilled water using a pH meter (Lab 850, SCHOTT Instruments, Deutschland, Germany). For determination of TA, the koji solution $(10 \% \mathrm{w} / \mathrm{v})$ was titrated using $0.1 \mathrm{M} \mathrm{NaOH}$ till $\mathrm{pH} 8.3$. The amount of $0.1 \mathrm{M} \mathrm{NaOH}$ consumed $(\mathrm{mL})$ was reported. Next, the acidity of koji was measured as follows: $1.5 \mathrm{~g}$ of koji was dissolved in 95\% ethanol/ether (1:2, v/v) and stirred on a hot plate (SMHS-3, Daihan Scientific Co., Wonju, Korea) at a speed of $620 \mathrm{rpm}$ for $20 \mathrm{~min}$ (SMHS-3, Daihan Scientific Co., Wonju, Korea). Then, $50 \mu \mathrm{L}$ of 1\% phenolphthalein solution was added and $0.1 \mathrm{~N}$ ethanol-potassium hydroxide $(\mathrm{KOH})$ was used for titration. The acidity was determined by a visual assessment and the amount of $\mathrm{KOH}$ per gram of koji was calculated.

Salinity, amino-type nitrogen, and alcohol content were measured using $2 \%(w / v)$ diluted koji with distilled water. For salinity analysis, the koji solution was titrated following the Mohr method. For determination of amino-type nitrogen, the koji solution was extracted using a shaking water bath (MaCturdy-30, Daihan Scientific Co., Gangwon-do, Korea) at a speed of $120 \mathrm{rpm}$ for an hour. Then, amino-type nitrogen was determined by the titration method using $0.1 \mathrm{~N} \mathrm{NaOH}$, until pH 8.4. After which, a $50 \mu \mathrm{L}$ of $1 \%$ phenolphthalein solution was used as a color indicator, and the results were expressed as a percent per milligram $(\mathrm{mg} / \%)$. To measure the alcohol content, the koji solution was filtered through Whatman no. 1 filter paper (Whatman International Ltd., Maidstone, England). Then, $1 \mathrm{~mL}$ of koji solution with $10 \mathrm{~mL}$ of $1 \mathrm{M} \mathrm{CrO} 3$ was mixed and let stand for $15 \mathrm{~min}$. Absorbance was determined at $600 \mathrm{~nm}$ using a UV spectrophotometer (BioDrop, MET Laboratories, Inc., Baltimore, MD, USA). The standard curve and results were expressed in terms of the percentage of alcohol content. Finally, reducing- and total-sugar content were measured using $1 \%(w / v)$ diluted koji and distilled water. Reducing sugar was analyzed by filtering $1 \mathrm{~mL}$ of koji solution through Whatman no. 2 filter paper (Whatman International Ltd., Maidstone, England). Then, this koji solution and the DNS solution (3,5-dinitrosalicylic acid) were mixed with $1 \mathrm{~mL}$ of distilled water with 1:1 ratio, and then it was heated at $100{ }^{\circ} \mathrm{C}$ for five minutes using a hot plate (SMHS-3, Daihan Scientific Co., Wonju, Korea) and immediately cooled on ice. The absorbance of each of test solution was recorded at $550 \mathrm{~nm}$ using a UV spectrophotometer (BioDrop, MET Laboratories, Inc., Baltimore, MD, USA). The standard curve and results were expressed in terms of glucose content $(\mathrm{mg} / \mathrm{g})$. Similarly, to measure the total sugar content, $1 \mathrm{~mL}$ of koji solution was mixed with of $5 \%$ phenol solution and $5 \mathrm{~mL}$ of $95 \% \mathrm{H}_{2} \mathrm{SO}_{4}$ and put in room temperature for $20 \mathrm{~min}$. The absorbance of each test solution was measured at $480 \mathrm{~nm}$ using a UV spectrophotometer (BioDrop, MET Laboratories, Inc., Baltimore, MD, USA). Glucose (mg/g) was used to record the standard curve and results.

\subsection{Enzymatic Activity Analysis}

Enzymatic activity, including amylase and protease activity, was measured following the method from a previous study [14,15], with minor modifications. For amylase activity, $3 \mathrm{~g}$ of $k o j i$ with $30 \mathrm{~mL}$ of purified water were homogenized using a vortex mixer (VM-10, Daihan Scientific Co., Wonju, Korea) and extracted in a shaking water bath (MaCturdy-30, Daihan Scientific Co., Wonju, Korea) at a speed of $120 \mathrm{rpm}$ for four hours. Then, centrifuged at a speed of $8279 \times \mathrm{g}$ at $4{ }^{\circ} \mathrm{C}$ for $15 \mathrm{~min}$ (1580MGR, Gyrozen, Daejeon, Korea). The supernatant of the centrifuged koji solution was used as a crude enzyme solution to determine the amylase activity. To measure the $\alpha$-amylase activity, $1 \mathrm{~mL}$ of koji solution was mixed with $2 \mathrm{~mL}$ of $1 \%$ starch solution at $\mathrm{pH} 7$ using a $0.2 \mathrm{M}$ sodium phosphate buffer and placed in a shaking water bath (MaCturdy-30, Daihan Scientific Co., Wonju, Korea) at $40{ }^{\circ} \mathrm{C}$ for $30 \mathrm{~min}$. To halt the reaction of amylase, $10 \mathrm{~mL}$ of $0.1 \mathrm{~N} \mathrm{HCl}$ was added and placed at room temperature for $30 \mathrm{~min}$. Next, of an iodine solution was added and absorbance was recorded at $660 \mathrm{~nm}$ using a UV spectrophotometer (BioDrop, MET Laboratories, Inc., Baltimore, MD, USA). A unit of $\alpha$-amylase activity was defined as the disappearance of 
an iodine binding $1 \%$ starch per minute in the assay reaction (unit/g). The $\beta$-amylase of the $k o j i$ samples was measured as follows: $1 \mathrm{~mL}$ of koji solution and $1 \mathrm{~mL}$ of $0.5 \%$ starch solution with $0.4 \mathrm{M}$ sodium acetate buffer at $\mathrm{pH} 4.8$ were thoroughly mixed in a shaking water bath (MaCturdy-30, Daihan Scientific Co., Wonju, Korea) at $30^{\circ} \mathrm{C}$ for $30 \mathrm{~min}$. Then, $2 \mathrm{~mL}$ of DNS solution (3, 5-dinitrosalicylic acid) was added and boiled at $100{ }^{\circ} \mathrm{C}$ for five minutes. Upon boiling, each koji solution was immediately cooled on ice and the absorbance was recorded at $550 \mathrm{~nm}$ using a UV spectrophotometer (BioDrop, MET Laboratories, Inc., Baltimore, MD, USA). A standard curve was made using a $0.2 \%$ maltose. The $\beta$-amylase activity was calculated according to the amount of maltose $(\mathrm{mg})$ produced by $1 \mathrm{~mL}$ of the koji solution for a minute. To determine protease activity, $2 \mathrm{~g}$ of the koji sample with $40 \mathrm{~mL}$ of distilled water was mixed and filtered through Whatman no. 1 filter paper (Whatman International Ltd., Maidstone, England). Three $\mathrm{ml}$ of $0.6 \%$ casein solution (acidic: $\mathrm{pH}$ 2.6; neutral: $\mathrm{pH}$ 7.0) with $1 \mathrm{~mL}$ of $k o j i$ solution was mixed and placed in a shaking water bath (MaCturdy-30, Daihan Scientific Co., Wonju, Korea) at $30^{\circ} \mathrm{C}$ for $10 \mathrm{~min}$. Then, $5 \mathrm{~mL}$ of $0.4 \mathrm{M}$ trichloroacetic acid (TCA) solution was added to the koji solution and let stand for $20 \mathrm{~min}$ at $37^{\circ} \mathrm{C}$ to halt the enzyme reaction. After which, the $k o j i$ solution was centrifuged at a speed of $1147 \times g$ for five minutes (1580 MGR, Gyrozen, Daejeon, Korea). One ml of Folin-Ciocalteau reagent was added to $2 \mathrm{~mL}$ of koji supernatant solution and then $5 \mathrm{~mL}$ of $0.4 \mathrm{M} \mathrm{Na}_{2} \mathrm{CO}_{3}$ was mixed in. After $30 \mathrm{~min}$, the absorbance at $660 \mathrm{~nm}$ was recorded using a UV spectrophotometer (BioDrop, MET Laboratories, Inc., Baltimore, MD, USA). Tyrosine (mg) was used to record a standard curve and a unit of protease activity was expressed based on the amount of tyrosine produced by $1 \mathrm{~mL}$ of the koji solution for one minute. All measurements were conducted in triplicates.

\subsection{Descriptive Analysis}

To determine the sensory characteristics of koji made with different kinds of raw materials, a descriptive analysis was conducted using a highly trained panel $(n=7)$ consisting of six females and one male, 22-38 years of age. Each panelist had more than $500 \mathrm{~h}$ of experience in sensory analysis of various food products using the Spectrum ${ }^{\mathrm{TM}}$ Method with a 15-point Universal scale. Thirty grams of koji were put in $70 \mathrm{~mL}$ white plastic cups $(70 \mathrm{~mm} \times 30 \mathrm{~mm})$ and labelled with random three-digit codes. The koji samples used for sensory evaluation were prepared two hours prior to evaluation and kept at room temperature until testing. Panelists received four-2 $\mathrm{h}$ training sessions to calibrate the use of the 15-point Universal scale and develop the sensory lexicon for each koji type. Only the aroma attributes of the koji were evaluated. Panelists took three minutes of rest between the evaluation of each sample to minimize a carry-over effect. All analysis was conducted in triplicate. Panelists were invited to an appreciation dinner upon completion of the evaluation.

\subsection{Statistical Analysis}

The results of the physiochemical characteristics and enzymatic activities of the koji samples were expressed as the mean \pm standard deviation of a triplicate analysis. A significant difference in the physiochemical and sensory characteristics of the koji types during the fermentation period was analyzed using a variance followed by Duncan's multiple range test at a level of $\alpha=0.05$. A principal component analysis (PCA) was conducted to determine the correlation between the physiochemical quality characteristics and sensory characteristics of each type of koji using XLSTAT software from 2018 (Addinsoft, Paris, France). All statistical analysis was performed using SPSS (version 25.0; IBM Co., Amork, NY, USA), except for the PCA.

\section{Results and Discussion}

\subsection{Comparison of the Physiochemical Quality Characteristics of koji}

The physiochemical quality characteristics of soybean, rice, and wheat koji are shown in Table 1. Significant differences in several quality attributes, including $\mathrm{pH}$, moisture content, $a^{*}$, acidity, titratable 
acidity (TA), reducing- and total-sugar content, and alcohol content, were observed among the three koji samples $(p<0.05)$.

Table 1. Comparison of physiochemical characteristics of three different $k o j i$ after $72 \mathrm{~h}$ fermentation.

\begin{tabular}{|c|c|c|c|c|c|}
\hline & & Soybean koji & Rice koji & Wheat koji & $p$-Value \\
\hline \multicolumn{2}{|c|}{ Moisture content $(\%)$} & $61.8 \pm 0.9^{a}$ & $51.1 \pm 4.3^{b}$ & $26.9 \pm 1.3^{c}$ & 0.00 \\
\hline \multirow{3}{*}{$\begin{array}{c}\text { Color } \\
\text { measurement }\end{array}$} & $L^{*}$ & $8.8 \pm 5.2$ & $7.6 \pm 2.7$ & $13.4 \pm 13.2$ & 0.46 \\
\hline & $a^{*}$ & $3.4 \pm 1.2^{\mathrm{a}}$ & $0.6 \pm 2.0^{b}$ & $0.0 \pm 2.0^{b}$ & 0.01 \\
\hline & $b^{*}$ & $4.4 \pm 2.0$ & $6.8 \pm 1.6$ & $4.6 \pm 1.9$ & 0.08 \\
\hline \multicolumn{2}{|c|}{$\mathrm{pH}$ value } & $6.2 \pm 0.8^{a}$ & $5.5 \pm 0.2^{b}$ & $5.7 \pm 0.3^{a, b}$ & 0.08 \\
\hline \multicolumn{2}{|c|}{ Titratable acidity (mL) } & $3.2 \pm 1.7^{\mathrm{a}}$ & $0.9 \pm 0.1^{b}$ & $0.8 \pm 0.4^{b}$ & 0.00 \\
\hline \multicolumn{2}{|c|}{ Acid value $(\mathrm{KOH} / \mathrm{g})$} & $21.4 \pm 4.0^{\mathrm{a}}$ & $6.7 \pm 1.7^{b}$ & $3.1 \pm 0.4^{\mathrm{c}}$ & 0.00 \\
\hline \multicolumn{2}{|c|}{ Salinity (\%) } & $10.0 \pm 0.4$ & $8.2 \pm 0.2$ & $10.3 \pm 0.3$ & 0.54 \\
\hline \multicolumn{2}{|c|}{$\mathrm{NH}_{2}-\mathrm{N}(\mathrm{mg} / \%)$} & $1.1 \pm 1.4$ & $1.2 \pm 0.8$ & $1.3 \pm 0.4$ & 0.22 \\
\hline \multicolumn{2}{|c|}{ Alcohol (g/\%) } & $3.8 \pm 1.2^{b}$ & $5.2 \pm 0.8^{a}$ & $4.3 \pm 0.7^{a, b}$ & 0.06 \\
\hline \multicolumn{2}{|c|}{ Reducing sugar (mg/g) } & $13.9 \pm 1.8^{b}$ & $90.3 \pm 43.1^{\mathrm{a}}$ & $15.2 \pm 5.1^{b}$ & 0.00 \\
\hline \multicolumn{2}{|c|}{ Total sugar (mg/g) } & $16.8 \pm 11.7^{c}$ & $107.5 \pm 10.9^{a}$ & $61.1 \pm 5.7^{b}$ & 0.00 \\
\hline
\end{tabular}

Numbers represent mean \pm standard deviation of triplicate analyses of each physiochemical characteristics. Numbers in a row that does not share same alphabetical letter represent significant differences at $\alpha=0.05$.

Soybean koji showed higher values in the moisture content, $\mathrm{pH}, a^{*}$, acidity, and TA compared to the other types of koji made with rice and wheat $(p<0.05)$. As for the moisture contents of koji samples, soybean $k o j i$ had $61.8 \%$, rice $k o j i$ had $51.1 \%$, and wheat koji had $26.9 \%$ respectively, and these values were significantly different to each other $(p<0.05)$. The reported moisture content of commercially-available doenjang was approximately 50-55\% [14]. Compared to the reported moisture content of doenjang, wheat koji had significantly lower moisture content than other koji samples as well as moisture content of doenjang. The low moisture content in wheat koji might be attributed to the fact that wheat koji is prepared with wheat flour, which has a lower moisture content at the beginning of the koji-process compared to rice and soybean. It is worth to note that the moisture contents of soybean, rice and wheat $k o j i$ in 0-h fermentation were $59 \%, 46.3 \%$, and $26 \%$, respectively. As seen in this study, the moisture content of the raw materials may have influenced the moisture content of the final koji products. The pHs of koji made with different ingredients were 6.2 (soybean koji), 5.5 (rice koji), and 5.7 (wheat koji), and no significant differences between samples were observed $(p>0.05)$. The $\mathrm{pH}$ ranges of koji were within the range of reported $\mathrm{pHs}$ in commercially-available doenjang samples, which correspond to 4.7-5.4 [14]. This is as expected because commercial doenjang making process is heavily dependent on koji, therefore the metabolites including organic acids in koji may have influenced the final $\mathrm{pH}$ of doenjang. Soybean koji had the highest values in TA and acidity. The results of the acidity measurements might be influenced by the presence of Aspergillus oryzae, which produces organic acid in the raw materials [16,17]. Salinity values of koji samples ranged from $8.2-10.3 \%$ and no significant difference was seen among samples $(p>0.05)$. No significant differences in amino-type nitrogen were also observed among the three koji samples. Previous studies reported an increase in amino-type nitrogen of about $0.7-1.5 \mathrm{mg} / \%$ over a $72 \mathrm{~h}$ fermentation period [11,17]. The level of amino-type nitrogen reported in this study for koji made with soybean, rice, and wheat is within the range of previously reported values. However, rice koji had the highest level in reducing- and total-sugar and alcohol contents followed by wheat and soybean koji $(p<0.05)$. Previous studies on the metabolite analysis of rice koji made with two different microorganisms (Aspergillus oryzae and Bacillus amyloliquefaciens) reported that rice koji made with $A$. oryzae has higher levels of sugars, sugar alcohols, and organic acids such as succinic, glyceric, fumaric, malic, kojic, citric, and gluconic acids [9]. These are the metabolites from carbohydrate metabolism. Therefore, the higher levels of reducing and total sugar in rice koji may be a 
result of the carbohydrate metabolism in rice, as most of the ingredients in rice koji are composed of carbohydrates. Soybean koji had the lowest level of sugar, which may be due to the high protein content in soybean. Soybean koji also had a low alcohol content and higher levels of acidity and TA compared to the other types of koji $(p<0.05)$. Previous studies reported that the early stage of fermentation is important for metabolite formation in koji, and that the production of alcohol occurs at an early stage in the fermentation process (between $0-24 \mathrm{~h}$ ), while organic acids were produced at the end of the fermentation process $[16,17]$.

\subsection{Enzymatic Activity Results}

The enzymatic activities of the three different types of koji are shown in Table 2. The enzymatic activities of koji depend on the characteristics of the raw materials, types of mold, fermentation time, and storage conditions $[6,18,19]$. Results of the amylase and protease activities in soybean, rice, and wheat koji were significantly different $(p<0.05)$. The $\alpha$-amylase activities of soybean, rice, and wheat koji were $35.7 \mathrm{unit} / \mathrm{g}, 34.8 \mathrm{unit} / \mathrm{g}$, and $36.3 \mathrm{unit} / \mathrm{g}$, respectively, and the $\alpha$-amylase activity of wheat koji was significantly higher than that of rice $k o j i(p<0.05)$. Similarly, rice koji showed higher $\beta$-amylase activities than the other two koji samples $(p<0.05)$. A high amylase activities of rice koji might be due to the nutritive value of rice [6], where rice is composed of more than $90 \%$ carbohydrates (mainly amylose) and less than $7 \%$ proteins, as a result of the milling process [20]. Higher content of amylase activities ( $\alpha$ - and $\beta$-) may be due to the higher amount of amylose content in the raw materials (in this case, rice). Protease activity can be used to measure the hydrolysis ability of a protein. The results of the protease activities in soybean koji were significantly higher than the protease activities in rice and wheat koji, which is consistent with previous studies that reported low protease activities in rice and barley koji during the fermentation process $[7,9,21]$. Lower protease activities in rice and wheat koji may be due to the lower protein content in the raw materials (i.e., rice and wheat flour), which limits the protease expression during the fermentation process [7]. When compared to the acidic protease activities of doenjang, which is around 70-110 unit/g for commercially-made doenjang and 90-120 unit/g for traditionally-made doenjang [14], acidic protease activities of soybean koji was still lower than acidic protease activities of doenjang. Similarly, neutral protease activities ranged from 44-130 unit/g for commercially-made doenjang, while neutral protease activities of traditionally-made doenjang ranged from 88-120 unit/g; these values were higher than neutral protease activities of soybean koji reported in this study. This indicates that protease activities continuously increase during doenjang fermentation process, which explains the increased levels of protein-degradation compounds responsible for distinctive flavors in doenjang [1].

Table 2. Enzymatic activities of three different koji after $72 \mathrm{~h}$ fermentation.

\begin{tabular}{|c|c|c|c|}
\hline Enzymatic Activities & Soybean $k o j i$ & Rice $k o j i$ & Wheat koji \\
\hline$\alpha$-amylase (unit/g) & $35.7 \pm 0.6^{a, b}$ & $34.8 \pm 0.5^{b}$ & $36.3 \pm 0.4^{\mathrm{a}}$ \\
\hline$\beta$-amylase (unit/g) & $48.3 \pm 4.4^{\mathrm{b}}$ & $75.1 \pm 2.4^{\mathrm{a}}$ & $52.0 \pm 8.0^{b}$ \\
\hline Acidic protease (unit/g) & $24.0 \pm 5.4^{\mathrm{a}}$ & $8.5 \pm 5.2^{b}$ & $1.5 \pm 1.1^{\mathrm{b}}$ \\
\hline Neutral protease (unit/g) & $13.5 \pm 1.8^{\mathrm{a}}$ & $15.1 \pm 2.4^{\mathrm{a}}$ & $1.2 \pm 2.2^{b}$ \\
\hline
\end{tabular}

All results of enzymatic activities were represented as mean \pm standard deviation. The alphabetic letter in the row for each $k o j i$ represented a significant difference $(p<0.05)$. Numbers in a row that does not share same alphabetical letter represent significant differences at $\alpha=0.05$.

\subsection{Descriptive Analysis Results}

The sensory profiles of soybean, rice, and wheat koji were characterized using a trained panel $(n=7)$, as shown in Table 3. The intensity of the three different koji samples was assessed using a 15-point Universal scale. The sensory lexicon for describing the aromatic characteristics of soybean, rice, and wheat koji was defined as followings: bean sprout, balsamic, soy sauce, cheonggukjang, cracker, solvent, rice powder, parboiled rice, overripe banana, syrup, wood, and roasted. The definitions 
and references for each aroma characteristic are included in Table 3. Significant aroma differences were observed between the three koji samples $(p<0.05)$.

Table 3. Descriptive sensory analysis about three koji samples using a trained panel $(n=7)$.

\begin{tabular}{|c|c|c|c|c|}
\hline Term & Definition & Soybean koji & Rice $k o j i$ & Wheat koji \\
\hline Bean sprout & $\begin{array}{l}\text { The aromatics associated with bean sprout (Ref: } \\
\text { steaming bean sprout in water for } 20 \mathrm{~min} \text { ) }\end{array}$ & $0.07^{\mathrm{a}}$ & $0.00^{\mathrm{a}}$ & $0.00^{\mathrm{a}}$ \\
\hline Balsamic & $\begin{array}{l}\text { The aromatics associated with balsamic } \\
\text { vineager (Ref: balsamic vinegar, Ottugi, } \\
\text { Anyang, Gyeonggi-do, Korea) }\end{array}$ & $0.20^{\mathrm{a}}$ & $0.00^{\mathrm{a}}$ & $0.00^{\mathrm{a}}$ \\
\hline Soy sauce & $\begin{array}{l}\text { The aromatics associated with } \\
\text { commercially-made soy sauce (Ref: } 501 \text { soy } \\
\text { sauce, Sempio }{ }^{\circledR} \text {, Icheon, Gyeonggi-do, Korea) }\end{array}$ & $0.86^{\mathrm{b}}$ & $1.67^{\mathrm{a}}$ & $0.47^{b}$ \\
\hline Cheonggukjang & $\begin{array}{l}\text { The aromactics associated with cheonggukjang } \\
\text { (Ref: Cheonggukjang, Pulmuone, Iksan, } \\
\text { Jellabuk-do, Korea) }\end{array}$ & $1.95^{\mathrm{a}}$ & $0.00^{\mathrm{b}}$ & $0.00^{\mathrm{b}}$ \\
\hline Cracker & $\begin{array}{l}\text { The aromatics associated with unsalted cracker } \\
\text { (Ref: Cham-cracker, Crown, Deajeon, Korea) }\end{array}$ & $0.40^{\mathrm{a}}$ & $0.00^{b}$ & $0.00^{\mathrm{b}}$ \\
\hline Solvent & $\begin{array}{l}\text { The aromatics associated with chemical } \\
\text { refrigerator }\end{array}$ & $0.27^{b}$ & $1.73^{\mathrm{a}}$ & $0.36^{b}$ \\
\hline Rice powder & $\begin{array}{l}\text { The aromatics associated with rice powder (Ref: } \\
\text { Organic rice powder, Momsrice, Gwangju, } \\
\text { Gyeonggi-do, Korea) }\end{array}$ & $0.00^{\mathrm{a}}$ & $0.06^{\mathrm{a}}$ & $0.01^{\mathrm{a}}$ \\
\hline Parboiled rice & $\begin{array}{c}\text { The aromatics associated with parboiled rice } \\
\text { (Ref: Instant rice without heating, CJ } \\
\text { Cheil-jedang, Gangneung, } \\
\text { Gangwon-do, Korea) }\end{array}$ & $0.00^{\mathrm{a}}$ & $0.07^{\mathrm{a}}$ & $0.00^{\mathrm{a}}$ \\
\hline $\begin{array}{l}\text { Overriped } \\
\text { banana }\end{array}$ & $\begin{array}{l}\text { The aromatics associated with overly-ripped } \\
\text { banana (Ref: overly-riped banana) }\end{array}$ & $0.00^{\mathrm{b}}$ & $1.83^{\mathrm{a}}$ & $0.00^{\mathrm{b}}$ \\
\hline Syrup & $\begin{array}{c}\text { The aromatics associated with maple syrup } \\
\text { (Ref: maple syrup, L.B. Maple Treat Corp, } \\
\text { Quebec, Canada) }\end{array}$ & $0.00^{\mathrm{b}}$ & $1.18^{\mathrm{a}}$ & $0.00^{\mathrm{b}}$ \\
\hline Wood & $\begin{array}{l}\text { The aromatics associated with wet wood (Ref: } \\
\text { hot steaming wet sauna) }\end{array}$ & $0.00^{b}$ & $0.00^{\mathrm{b}}$ & $0.47^{\mathrm{a}}$ \\
\hline Roasted & $\begin{array}{l}\text { The aromatics associated with popcorn (Ref: } \\
\text { Lohi popcorn, Sajo, Yeongcheon, } \\
\text { Gyeongsangbuk-do, Korea) }\end{array}$ & $0.00^{\mathrm{b}}$ & $0.00^{\mathrm{b}}$ & $2.31^{\mathrm{a}}$ \\
\hline
\end{tabular}

Numbers represent mean of intensities of each term rated by highly trained panel ( $n=5)$ using 15-pt Universal scale.

Numbers in a row that does not share same alphabetical letter represent significant differences at $\alpha=0.05$.

Soy sauce and solvent were commonly present aroma characteristics among the three types of koji. Compared with previous studies of the flavor of doenjang, the common sensory characteristics between doenjang and koji in the present study were balsamic, soy sauce, and solvent [22-25]. The characteristics of bean sprout, balsamic, cheonggukjang, and cracker were strongly identified in soybean koji. In particular, soybean koji had higher intensities of cheonggukjang and cracker aromatics compared to rice and wheat koji. Previous studies analyzing the flavor of doenjang using a descriptive analysis defined soybean-related characteristics as cooked soybean, roasted soybean, roasted bean/roasted nutty, and cheonggukjang [23-25]. The results from this study indicate a similarity in the aroma characteristics in soybean koji and doenjang, which is as expected because commercially-made doenjang typically utilizes soybean koji. Rice koji had higher characteristics in soy sauce and solvent aromatics than soybean and wheat koji. Rice koji also had higher sweetness-related characteristics, such as overripe banana and syrup, compared to the other koji samples $(p<0.05)$. As mentioned earlier, these sweet-related aroma characteristics may have been attributed from the carbohydrate metabolism of rice, as rice had higher content of starch than soybean and wheat. Combination of higher carbohydrate content and high amylase activities ( $\alpha$ - and $\beta$-) may have influenced the sweet-like aroma 
characteristics of rice koji. The aromatics of rice powder were only identified in rice and wheat koji. The characteristics of wood and roasted were higher in wheat koji than the other koji samples $(p<0.05)$.

\subsection{Correlating Physiochemical Quality Characteristics, Enzymatic Activities, and Descriptive Analyses Result}

A principal component analysis (PCA) biplot of the three types of koji based on physiochemical quality characteristics, enzymatic activities, and descriptive analyses can be found in Figure 1. A PCA biplot shows where each koji sample is located in a sensory and quality characteristics map.

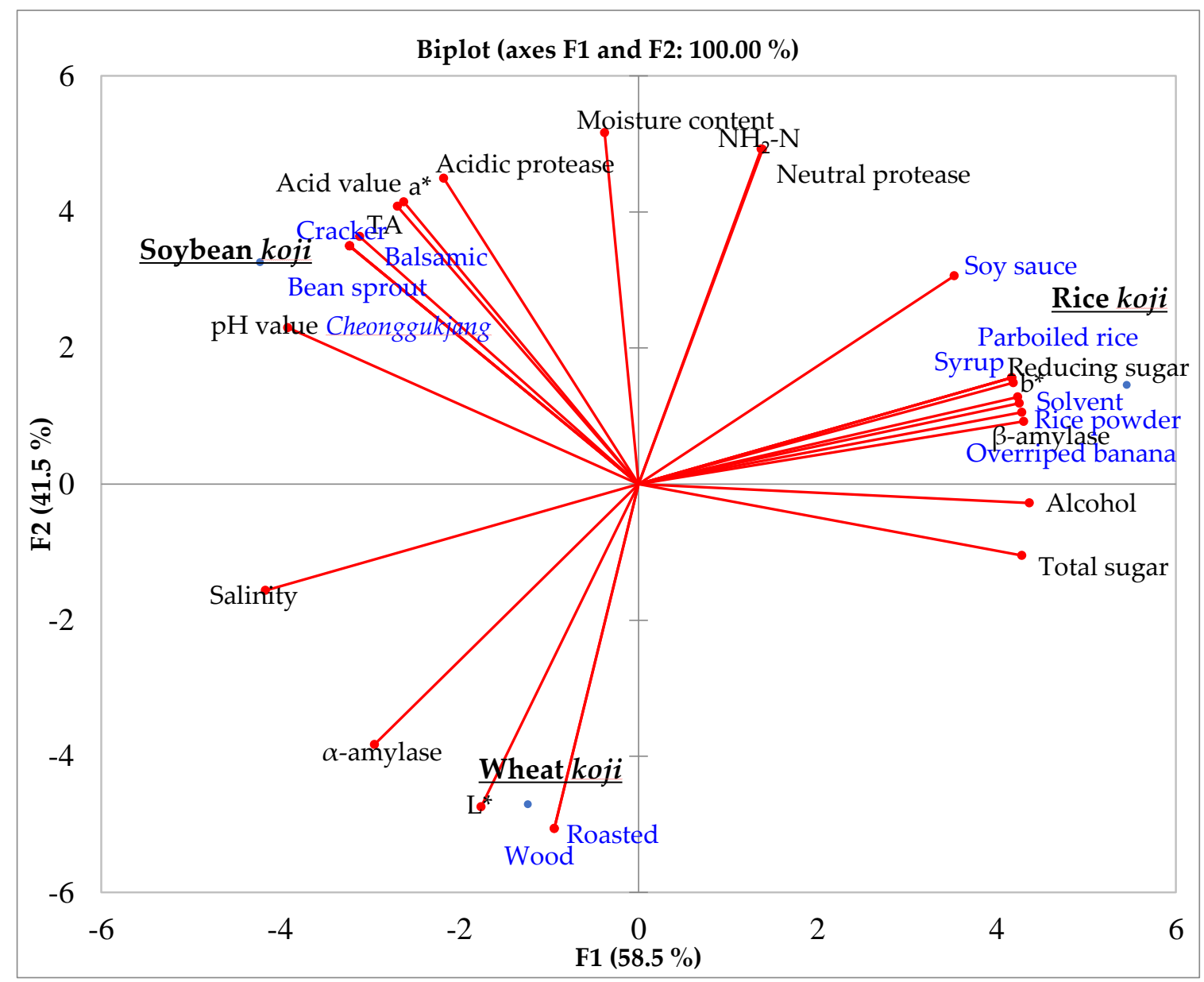

Figure 1. Principal Component Analysis Biplot of physiochemical and sensory characteristics of three koji made with different sources (soybean, rice and wheat).

In this map, soybean, rice, and wheat koji were differentiated by their quality, enzymatic, and sensory characteristics. Soybean koji showed a high correlation with the acidity, TA, $\mathrm{pH}$, and acidic protease, and was characterized by balsamic, cracker, and cheonggukjang aromatics. This result is in agreement with what was stated in earlier in this paper. Aspergillus oryzae is known to produce hydrolytic enzymes, and thus the amino-acid degradation process from hydrolytic enzymes produced by $A$. oryzae may have influenced organic-acid and amino-acid production in soybean koji [7]. These high protease activities and consequent amino-acid degradation process in soybean koji, may have created the balsamic, bean sprout cheonggukjang and cracker aroma characteristics. Previous study reported that Cheonggukjang, and balsamic aromatics are typical aroma characteristics of traditionally-made doenjang in which have high protease and other enzymatic activities [25]. The finding from this study is in agreement with previously reported results. Rice koji showed a high correlation with sweetness-related attributes, such as reducing- and total-sugar content, alcohol content, and $\beta$-amylase. The carbohydrate metabolism from rice starch may have influenced the high levels of reducing and total sugars in rice 
$k o j i$, as well as the alcohol content. The presence of alcohol in rice koji may have influenced its aromatic characteristics, such as overripe banana and syrup. The characteristic aromatics of rice koji were rice powder, solvent, overripe banana, syrup, parboiled rice, and soy sauce. Previous studies also reported that doenjang samples high in total and reducing sugar showed a high correlation with sweetness aromatics [14]. The wheat koji sample was characterized by a high $L^{*}$ value and woody and roasted aromatics. The high $L^{*}$ value of wheat $k o j i$ indicates a whiter color, which is a distinctive characteristic of wheat koji in comparison to the other types.

\section{Conclusions}

This study established the physiochemical quality characteristics, enzymatic activities, and sensory aromatic characteristics of soybean, rice, and wheat koji. Differences were observed in the three types of koji prepared with different raw materials. Soybean koji had high levels of $\mathrm{pH}$, moisture, acidity, and TA, as well as soybean-related aromatics characterized by bean sprout, cracker, and cheonggukjang. Rice koji had high levels of total and reducing sugar as well as aromatics characterized by overripe banana, syrup, solvent, and parboiled rice. Wheat koji had a whiter color than the other samples, and woody and roasted aromatics. The differences between the three koji samples were determined by the different raw ingredient of each type.

Author Contributions: H.H.H., contributed to the manuscript preparation, data collection and draft of manuscript write-ups; M.K.K., contributed to the data analysis and interpretation and manuscript write-ups. All authors have read and agreed to the published version of the manuscript.

Funding: This research was supported by Basic Science Research Program through the National Research Foundation of Korea (NRF) funded by the Ministry of Science, ICT \& Future Planning (grant number; NRF-2017R1D1A3B03032520, and NRF-2020R1C1C1011279).

Conflicts of Interest: The authors declare no conflict of interest.

\section{References}

1. Jo, Y.J.; Cho, I.H.; Song, C.K.; Shin, H.W.; Kim, Y.S. Comparison of fermented soybean paste (Doenjang) prepared by different methods based on profiling of volatile compounds. J. Food Sci. 2011, 76, C368-C379. [CrossRef] [PubMed]

2. Kim, M.K.; Lee, K.G. Correlating consumer perception and consumer acceptability of traditional Doenjang in Korea. J. Food Sci. 2014, 79, S2330-S2336. [CrossRef] [PubMed]

3. Park, K.Y.; Hwang, K.M.; Jung, K.O.; Lee, K.B. Studies on the standardization of Doenjang (Korean Soybean Paste) 1. Standardization of Manufacturing Method of Doenjang by Literature. J. Korean Soc. Food Sci. Nutr. 2002, 31, 343-350. [CrossRef]

4. Ito, K.; Yoshida, K.; Ishikawa, T.; Kobayashi, S. Volatile compounds produced by the Fungus Aspergillus oryzae in Rice koji and their changes during cultivation. J. Ferm. Bioeng. 1990, 70, 169-172. [CrossRef]

5. Chancharoonpong, C.; Hsieh, P.C.; Sheu, S.C. Enzyme production and growth of aspergillus oryzae S. on soybean koji fermentation. APCBEE Procedia 2012, 2, 57-61. [CrossRef]

6. Jun, J.Y.; Lee, M.H.; Jeong, I.H.; Jung, M.J.; Kim, B.M. Effects of seaweeds on rice koji production and enzyme activity. Korean J. Fish. Aquat. Sci. 2018, 51, 369-375. [CrossRef]

7. Bechman, A.; Phillips, R.D.; Chen, J. Changes in selected physical property and enzyme activity of rice and barley koji during fermentation and storage. J. Food Sci. 2012, 77, M318-M322. [CrossRef]

8. Kim, B.M.; Park, J.H.; Kim, D.S.; Kim, Y.M.; Jun, J.Y.; Jeong, I.H.; Nam, S.Y.; Chi, Y.M. Effects of rice koji inoculated with Aspergillus Iuchuensis on the biochemical and sensory properties of a sailfin sandfish (Arctoscopus japonicus) fish sauce. Int. J. Food Sci. Technol. 2016, 51, 1888-1899. [CrossRef]

9. Lee, D.E.; Lee, S.; Jang, E.S.; Shin, H.W.; Moon, B.S.; Lee, C.H. Metabolomic profiles of Aspergillus oryzae and Bacillus amyloliquefaciens during rice koji fermentation. Molecules 2016, 21, 773. [CrossRef]

10. Kim, D.Y.; Kwon, D.J. Quality characteristics of doenjang manufactured with soybean koji. Korean J. Food Preserv. 2014, 21, 434-441. [CrossRef]

11. Yong, F.M.; Wood, B.J. B Biochemical changes in experimental soy sauce koji. Int. J. Food Sci. Technol. 1977, 12, 163-175. [CrossRef] 
12. Chiou, R.Y.Y.; Cheng, S.L. Isoflavone transformation during soybean koji preparation and subsequent miso fermentation supplemented with ethanol and NaCl. J. Agric. Food Chem. 2001, 49, 3656-3660. [CrossRef] [PubMed]

13. Kim, Y.G.; Lyu, J.; Kim, M.K.; Lee, K.G. Effect of citrulline, urea, ethanol, and urease on the formation of ethyl carbamate in soybean paste model system. Food Chem. 2015, 189, 74-79. [CrossRef]

14. Kim, M.K.; Chung, H.J.; Bang, W.S. Correlating physiochemical quality characteristics to consumer hedonic perception of traditional Doenjang (fermented soybean paste) in Korea. J. Sens. Stud. 2018, 33, e12462. [CrossRef]

15. Xiao, Z.; Storms, R.; Tsang, A. A quantitative starch-iodine method for measuring alpha-amylase and glucoamylase activities. Anal. Biochem. 2006, 351, 146-148. [CrossRef] [PubMed]

16. Lee, S.; Kim, D.H. Changes in Physicochemical properties of low-salt Doenjang during fermentation. J. Korean Food Sci. Technol. 2012, 44, 592-599. [CrossRef]

17. Kim, J.S.; Lee, J.H.; Chang, Y.E.; Kim, G.C.; Kim, K.M. The quality characteristics of rice mash by mixing ratios of rice and rice koji. J. Korean Soc. Food Sci. Nutr. 2013, 42, 2035-2041. [CrossRef]

18. Chutmanop, J.; Chuichulcherm, S.; Chisti, Y.; Srinophakun, P. Protease production by Aspergillus oryzae in solid-state fermentation using agroindustrial substrates. J. Chem. Technol. Biotechnol. 2008, 83, 1012-1018. [CrossRef]

19. Lee, G.R.; Ko, Y.J.; Kim, E.J.; Kim, I.H.; Shim, K.H.; Kim, Y.G.; Ryu, C.H. Quality characteristics of wheat Doenjang according to mixing ratio of Meju. Korean J. Food Preserv. 2013, 20, 191-198. [CrossRef]

20. Choi, I.D. Physicochemical properties of rice cultivars with different amylose contents. J. Korean Soc. Food Sci. Nutr. 2010, 39, 1313-1319. [CrossRef]

21. Su, N.W.; Wang, M.L.; Kwok, K.F.; Lee, M.H. Effects of temperature and sodium chloride concentration on the activities of proteases and amylases in soy sauce koji. J. Agric. Food Chem. 2005, 53, 1521-1525. [CrossRef]

22. Lee, S.J.; Ahn, B. Comparison of volatile components in fermented soybean pastes using simultaneous distillation and extraction (SDE) with sensory characterization. Food Chem. 2009, 114, 600-609. [CrossRef]

23. Kim, H.G.; Hong, J.H.; Song, C.K.; Shin, H.W.; Kim, K.O. Sensory characteristics and consumer acceptability of fermented soybean paste (Doenjang). J. Food Sci. 2010, 75, S375-S383. [CrossRef] [PubMed]

24. Kim, M.K.; Kwak, H.S.; Kim, M.J.; Kim, S.S. Identification of sensory characteristics that drive consumer preferences of commercially mass-produced doenjang in Korea. J. Sens. Stud. 2018, 33, e12323. [CrossRef]

25. Lee, J.H.; Jeong, D.W.; Kim, M.K. Influence of bacterial starter cultures on the sensory characteristics of Doenjang, a fermented soybean paste, and their impact on consumer hedonic perception. J. Sens. Stud. 2019, 34, e12508. [CrossRef]

(C) 2020 by the authors. Licensee MDPI, Basel, Switzerland. This article is an open access article distributed under the terms and conditions of the Creative Commons Attribution (CC BY) license (http://creativecommons.org/licenses/by/4.0/). 